\title{
Strain Assessment in Surgically Resected Inflammatory and Neoplastic Bowel Lesions
}

\author{
Bestimmung des Strain bei chirurgisch-resezierten entzündlichen \\ und neoplastischen Darmläsionen
}

Authors

Affiliations
R. F. Havre' ${ }^{1}$, S. Leh² ${ }^{2}$ O. H. Gilja ${ }^{3}$, S. Ødegaard', J. E. Waage ${ }^{4}$, G. Baatrup ${ }^{5}$, L. B. Nesje

Affiliation addresses are listed at the end of the article.

\author{
Key words \\ Q ultrasound \\ - adenocarcinoma \\ - Crohn's disease \\ - strain ratio \\ - ex-vivo
}

received 14.11.2011

accepted $\quad 15.9 .2012$

\section{Bibliography}

DOI http://dx.doi.org/

10.1055/s-0032-1325535

Published online: November 15 ,

2012

Ultraschall in Med 2014; 35 :

149-158 @ Georg Thieme

Verlag KG Stuttgart · New York

ISSN 0172-4614

\section{Correspondence}

\section{Dr. Roald Flesland Havre}

Institute of Medicine, University of Bergen, Haukeland University Hospital

Jonas Lies vei 65

5021 Bergen

Norway

Tel.: ++47/5/5973079

Fax: ++47/5/5975890

havren70@gmail.com

\section{Abstract \\ $\nabla$}

Purpose: To investigate whether ultrasoundbased strain imaging can discriminate between colorectal adenocarcinomas and stenotic Crohn's lesions in newly resected surgical specimens. Materials and Methods: Resected surgical specimens from 27 patients electively operated for colorectal tumors or stenotic lesions from Crohn's disease were prospectively examined with ultrasonography using a Hitachi HV 900 US scanner with real-time elastography (RTE). Three different methods were applied to assess tissue strain: A four-level categorical visual classification, a continuous visual analog scale (VAS, 0 -100) and a strain ratio (SR) measurement between the lesion and surrounding reference tissue. The imaged sections were marked and subsequently examined by a pathologist. Results from RTE were evaluated according to diagnosis, degree of fibrosis, inflammatory parameters, tumor stage and grade.

Results: 16 sections from Crohn's lesions, $18 \mathrm{sec}$ tions from adenocarcinomas and 4 sections from adenomas were examined. Both adenocarcinomas and Crohn's lesions were found to be harder than the surrounding tissue, but they could not be discriminated from each other by any of the strain imaging evaluation methods. All adenocarcinomas had significantly higher strain ratios than adenomas. The categorical classification differentiated poorly between Crohn's lesions, adenocarcinomas and adenomas. Categorical evaluation and VAS score showed fair interobserver agreement. SR measurements provided semi-quantitative strain data and added improved information about elasticity properties, despite substantial intra-observer variation.

Conclusion: Sonoelastography with SR measurements and visual evaluation of strain differences could not differentiate stenotic Crohn's lesions from adenocarcinomas in resected bowel speci-

\section{Zusammenfassung \\ $\nabla$}

Ziel: Untersuchung, inwieweit ultraschallbasiertes Strain-Imaging zwischen kolorektalen Karzinomen und stenotischen Crohn-Herdläsionen bei frisch resezierten chirurgischen Proben unterscheiden kann.

Material und Methoden: Resezierte chirurgische Proben von 27 Patienten nach Operation wegen kolorektaler Tumore oder stenotischer MorbusCrohn-Läsionen wurden prospektiv mit einem Hitachi HV-900-US-Gerät mit Echtzeit-Elastografie (RTE) untersucht. Zur Bestimmung der Gewebefestigkeit wurden drei verschiedene Methoden angewandt: Eine vierstufige kategorische visuelle Klassifizierung, eine kontinuierliche visuelle Analogskala (VAS, 0-100) und Bestimmung der Strain-Ratio (SR) zwischen dem Herd und dem umliegenden Referenzgewebe. Die abgebildeten Schnitte wurden markiert und sofort von einem Pathologen untersucht. Die Ergebnisse der RTE wurden je nach Diagnose, Fibrosegrad, Entzündungsparametern und Stadium und Grad des Tumors bewertet.

Ergebnisse: Es wurden 16 Schnitte von MorbusCrohn-Herdläsionen, 18 von Adenokarzinomen und 4 von Adenomen untersucht. Sowohl Adenokarzinome als auch Crohn-Herdläsionen waren steifer als das umliegende Gewebe, aber sie konnten mit keiner der Strain-Imaging-Bewertungsmethoden voneinander unterschieden werden. Alle Adenokarzinome hatten eine signifikant höhere Strain-Ratio als Adenome. Die kategorische Klassifizierung konnte nur schlecht zwischen Crohn-Herdläsionen, Adenokarzinomen und Adenomen differenzieren. Kategorische Bewertung und VAS-Auswertung zeigten eine gute Interobserverübereinstimmung. Die SR-Messungen führten zu semiquantitativen Strain-Werten und lieferten zusätzliche Informationen über die elastischen Eigenschaften, trotz einer beträchtlichen Intraobservervariation. 
mens. A small number of adenomas were found to be significantly softer than adenocarcinomas using the same evaluation methods. The tumor stage or grade did not have a significant impact on the elastography results.
Schlussfolgerung: Die Sonoelastografie mit SR-Bestimmungen und visueller Bewertung der Strain-Unterschiede kann bei resezierten Darmproben nicht zwischen stenotischen Crohn-Herdläsionen und Adenokarzinomen unterscheiden. Eine kleine Zahl an Adenomen zeigte sich signifikant weicher als Adenokarzinome unter Verwendung der gleichen Bewertungsmethoden. Stadium und Grad des Tumors hatten keinen signifikanten Einfluss auf die elastografischen Befunde.

\section{Introduction}

Differentiation between benign and malignant tissue is a major challenge in medical imaging. Tissue samples are usually necessary for a reliable diagnosis, but they may be difficult to obtain. Pathological changes may alter tissue structure and hence its elastic properties. New imaging modalities have been introduced as potential tools for the discrimination between malignant lesions and benign tissue based on changes in elasticity or strain distribution patterns [1]. Real-time elastography (RTE) is an ultrasound-based technique in which the distribution of strain is mapped when soft tissue is exposed to repetitive stress. The method was described by Ophir et al. and referred to as quasi-static elastography [2]. Several methods for registering strain or elasticity using different forces to induce tissue deformation leading to recordable displacements or shear waves have subsequently emerged $[3,4]$. These techniques have been used to characterize tissue in focal lesions, contracting organs, such as the heart [5, 6], stomach [7], and pancreas [8], or in liver fibrosis $[9,10]$. Hard tissue is characterized by low strain, while softer areas show higher strain. RTE has shown promising results for differentiating between malignant and benign lesions in breast lumps [11], prostate tumors [12,13], thyroid nodules [14-16], lymph nodes $[17,18]$ and the pancreas $[8,19]$. Both malignant tumors and chronic inflammation may lead to the formation of soft tissue fibrosis [20, 21]. Fibrosis formation in malignant tumors is called desmoplasia and may contribute to increased tissue hardness through several mechanisms involving tumor cells, stromal cells and the extracellular matrix [22]. Malignant tumors are also usually characterized by increased interstitial pressure, a feature that decreases quickly in devascularized tissue [23 - 25]. In this study, RTE was performed on surgically resected bowel specimens containing benign or malignant lesions using one categorical classification system and two semi-quantitative methods for relative strain assessment. Our aim was to evaluate whether RTE could differentiate lesions caused by inflammation from malignant neoplastic lesions using qualitative and semiquantitative methods for strain assessment. Furthermore, we examined whether strain ratio (SR) measurements were affected by changes in the elasticity dynamic range (E-dyn). Finally, we also wanted to correlate elastography results to a histological semiquantification of fibrosis, inflammation parameters and tumor description.

\section{Material and methods \\ $\nabla$}

Patients referred for elective bowel resection were recruited for this feasibility study from May 2008 to June 2009. All patients signed an informed consent to participate. The study was approved by the Regional Committee for Medical and Health Re- search Ethics in Western Norway and was conducted according to the Helsinki Declaration.

38 lesions from 27 patients were examined, 16 sections from Crohn's stenoses in 9 different patients, 18 sections from adenocarcinomas in 16 patients and 4 sections from adenomas in 3 different patients. One cancer patient had a synchronous adenoma and another had two synchronous adenocarcinomas. Two adenomas were separate lesions from the same patient. In one patient with a multilobular tumor, two different tumor sections were included as separate lesions. In the Crohn's disease specimens, separate skip lesions as well as the proximal and distal end of some longer stenoses were included as individual lesions.

The observer was not blinded to the indication for surgery, but the final diagnosis was confirmed by histopathology after the examination and image evaluation.

Newly resected specimens were collected from the operating room, rinsed in water and subsequently examined by ultrasound with RTE in a specially designated chamber. A 2-cm layer of hard paraffin wax covered the bottom of the chamber in order to limit US reflections and to provide hold for the needles used for fastening the specimens. A 1.5-cm layer of flexible agar (Agar No.1, $1 \%$, Oxoid Ltd, Basingstoke Hants, UK) was placed on top of this to make a flexible and echo-free background for ultrasound scanning. The scanning plane of a captured elastogram was marked on the specimen with 3 identically colored needles ( $\bullet$ Fig. 1 ). The specimen was then fixed in a $4 \%$ formalin solution for 3-7 days before a pathological examination was performed to obtain a histological confirmation of diagnosis.

\section{Ultrasound equipment}

A Hitachi Hi Vision 900 ultrasound scanner with software version V16 - 04 STEP 2 and a L54 M linear probe with frequencies 9 $13 \mathrm{MHz}$ (Hitachi Medical Corporation, Tokyo, Japan) were used in the study. The elastography modality was developed for freehand application, and small repetitive compression/decompression movements of the probe were used to provide stress and induce tissue strain. With this method, relative strain values in different areas are calculated based on the assumption that stress is evenly distributed over the region of interest (ROI). A color map showing the strain in individual image elements as compared to the mean strain of the whole ROI is produced. The color distribution depends on the selected level of the E-dyn. A graphic indicator on the display shows when there is sufficient strain to produce an elastogram. The applied strain imaging algorithm records changes in echo positions between consecutive radio frequency frames using the extended combined autocorrelation method (ECAM), which is an extension of the original quasi-static elastography [26, 27].

We used the following parameter settings for RTE: Frame reject: 6 , noise reject: 4 , persistence: $2-5$, smoothing: $2-3$. The VAS and categorical scores were determined using E-dyn level 4 (default level). SR examinations were also recorded at E-dyn levels 2 and 


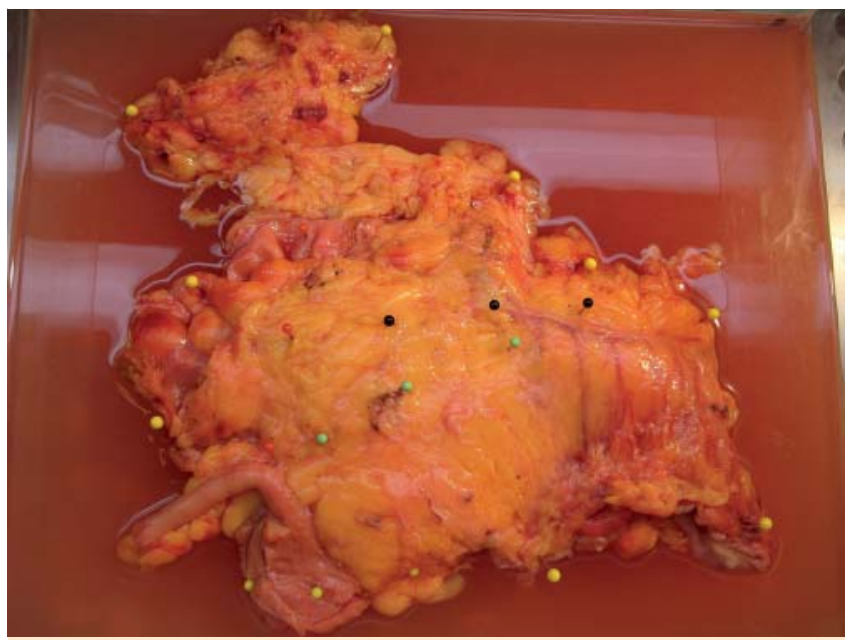

Fig. 1 The surgical preparations were examined in a transparent plexiglass chamber with the bottom covered with solid paraffin wax and a separate layer of $1.5 \mathrm{~cm}$ of $1 \%$ agar. The tissue was fixed to the agar layer with needles (yellow color) and the sections examined with B-mode US and elastography were marked with three needles with the same head-color (red, black, green) in order to define the position of the lesions and the scanning direction.

Abb. 1 Die Untersuchung der chirurgischen Präparate erfolgte in einer transparenten Plexiglaskammer, deren Boden mit einer festen Paraffinschicht und einer $1,5 \mathrm{~cm}$ dicken separaten Schicht bestehend aus $1 \%$ Agar bedeckt war. Das Gewebe wurde mit Nadeln (gelbe Farbe) auf der Agarschicht fixiert und die mittels Graustufenultraschall und Elastografie untersuchten Bereiche wurden mit drei gleichfarbigen Nadeln (Kopf in rot, schwarz, grün) markiert, um die Position der Läsionen und die Messrichtung festzulegen.

6. The frame rate varied between 9 and 14 depending on the selected ROI size.

\section{Methods for strain assessment}

We applied a categorical classification based on the color distribution within the lesion as originally described for pancreatic lesions by Janssen et al. [28]. In this classification, three basic patterns of color distribution are recognized: Type 1 is relatively homogeneous, type 2 has 2 or 3 different colors and type 3 has a honeycomb pattern. The colors present are represented by the subsequent letters usually indicating a declining proportion in the lesion: $\mathrm{A}=$ blue, $\mathrm{B}=$ green/yellow and $\mathrm{C}=$ red. 32 lesions ( $92 \%$ ) were classified according to this system and fell into five categories: 1B: homogeneously green, 2BA: green > blue, 2AB: blue > green, $1 \mathrm{~A}$ : homogeneously blue and $2 \mathrm{~A}-\mathrm{B}-\mathrm{C}$ : presence of blue, green and red without one of the colors being classified as more prominent.

A visual analog scale (VAS) consisted of a 100-mm line where the observer marked the assumed level of the lesion's hardness as assessed by elastography at E-dyn level 4. If the lesion was regarded as equal to the surrounding tissue, the mark was set at $50 \mathrm{~mm}$. Lesions appearing harder were marked between 50 and $100 \mathrm{~mm}$ and softer lesions were marked between 0 and $50 \mathrm{~mm}$. Assessments using the VAS score and visual categorical score were repeated by a trained observer blinded to the clinical data using video clips of the elastography seen in Windows Media Player (Microsoft Inc., Ca, USA). The results were compared to those obtained in the original scoring by the non-blinded observer.
The third strain evaluation method was a semi-quantitative measurement of SR comparing the reference tissue (B) and the lesion (A) using the following formula:

Strain ratio $=\frac{\text { Mean strain in reference }(B)}{\text { Mean strain in lesion }(A)}$

SR is a built-in scanner software function and was first introduced in breast scanning and was called the "fat-lesion ratio". It compares the mean strain in a user-selected portion of the reference tissue with a similarly selected part of the lesion, assuming that both areas have been subjected to the same amount of stress. We selected circular areas of reference tissue at the same depth and with approximately the same size as the lesion for all measurements ( $\bullet$ Fig. 2). In most cases, the central area of the lesion was selected for calculation (area A). However, if the lesions had reproducible differences in tissue hardness, the hardest area was selected as area A. Pericolic or mesenteric fat and connective tissue as well as parts of the normal bowel wall could be included in the reference area. SR measurements were performed on representative image frames with sufficient signal quality. Measurements were usually repeated 3 times on E-dyn levels 2, 4 and 6, respectively, thus yielding 9 SR measurements per lesion. However, only 3 SR measurements were recorded in three lesions. (E-dyn scale: 1 -8).

\section{Pathological evaluation}

One dedicated pathologist conducted all of the pathological examinations. The pathologist was assisted by the person who performed the ultrasound to ensure the correct orientation of tissue planes according to the previous US elastography examination during the gross examination of the formalin-fixed specimens. Whole mount slices with a thickness of $2 \mathrm{~mm}$ were taken according to the needle marks, inked for orientation and processed by standard procedures. Haematoxylin-eosin-stained sections were investigated for the following parameters of inflammation in cases of Crohn's disease: ulceration, granulation tissue, fissure ulcers, fistula, abscess, cryptitis, and lymphoplasmacytic inflammation. A fibrosis score was determined in all cases. Lymphoplasmacytic inflammation and fibrosis were graded semi-quantitatively as absent (0), slight (1), moderate (2), or severe (3).

The fibrosis score was based on a semi-quantitative visual evaluation performed by one pathologist. In order to validate this score, the same pathologist determined a second score for all lesions one year after the first scoring. A Kappa score of 0.37 was obtained, indicating fair reproducibility of the fibrosis score.

\section{Statistical analysis}

The VAS scores were found to be within the limits of normal distribution for adenomas, Crohn's lesions and adenocarcinomas as tested with the Shapiro-Wilk test, and comparisons between the groups were based on mean values with standard deviations in each group. When evaluating SR differences, the median of repeated SR measurements in each lesion was selected for further quantitative analysis. When comparing the three diagnostic groups of lesions, the mean of these SR medians was calculated within each group. The median SR results from Crohn's lesions and adenocarcinomas were not distributed normally. A log transformation was attempted, but did not yield a normal distribution. We had included one to three separate lesions from the surgical specimens due to skip lesions in Crohn's lesions and some synchronous neoplastic lesions. Consequently, the untransformed data were analyzed using a generalized estimating equations 

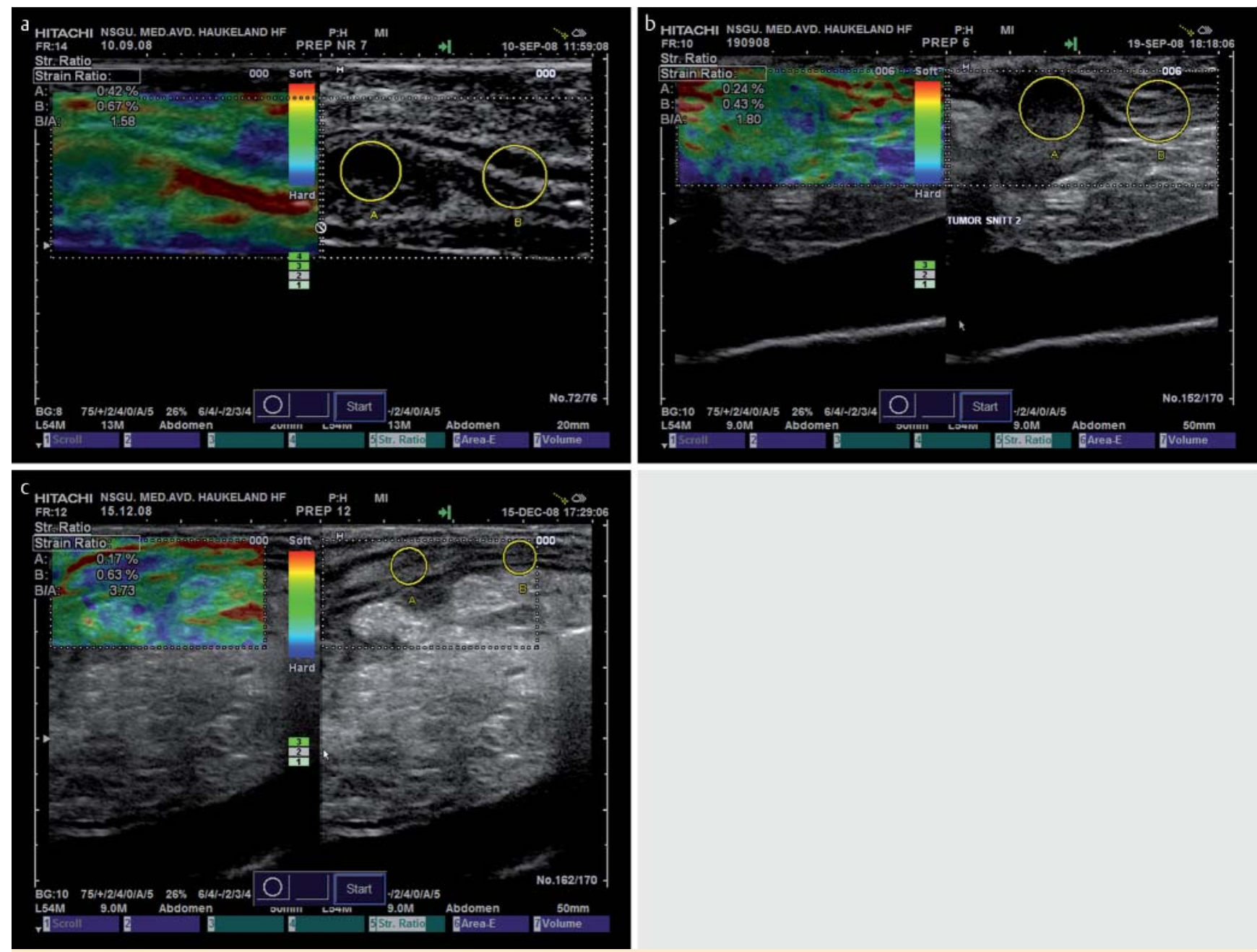

Fig. 2 Split-screen images showing B-mode ultrasound image on the right side and B-mode image with elastogram on the left. The displayed colors represent the degree of strain in the tissue covered by the region of interest. The strain ratio is calculated by the mean strain in the reference tissue (area B) divided by the mean strain in the lesion area (area A). The B-mode image is used for placing the areas $A$ and $B$ for strain ratio calculation. Images represent: a: Adenoma (SR 1.58), b: Adenocarcinoma (SR 1.80) and c: Crohn's lesion (SR 3.73).

(GEE) model allowing analysis of both related and unrelated observations. In this model, SR and VAS results for Crohn's lesions and adenomas were compared to the corresponding results for adenocarcinomas, which served as a reference. For comparison of SR measurements at E-dyn levels 2, 4 and 6, we used a Spearman's rho correlation and Wilcoxon-Mann-Whitney test for paired differences between the medians of three recorded SR measurements at each E-dyn level. The significance level was adjusted to apply for 3 measurements: $p=0.05 / 3=0.017$. This test also provided information about the repeatability of SR measurements in the individual lesions.

The interobserver agreement for categorical scores was assessed using Cohen's Kappa, which expresses the agreement controlled for agreement by chance and is considered a conservative measurement of interobserver agreement. The Kappa values were interpreted in the following manner: $0=$ no agreement, 0 $0.20=$ slight agreement, $0.21-0.40=$ fair agreement, $0.41-$ $0.60=$ moderate agreement, $0.61-0.80=$ substantial agreement,

Abb. 2 Splitscreen-Darstellungen zeigen das B-Bild auf der rechten Seite und das B-Bild mit Elastogramm zur Linken. Die dargestellten Farben stellen den Strain-Grad des Gewebes in der „Region of Interest“ an. Die Strain-Ratio wird berechnet aus dem mittleren Strain des Referenzgewebes (Bereich B) geteilt durch den mittleren Strain der Läsion (Bereich A). Das B-Bild wird benötigt, um die Bereiche A und B zu platzieren und die Strain-Ratio zu berechnen. Die Bilder stellen dar: a: Adenom (SR 1,58), b: Adenokarzinom (SR 1,80) und c: Crohn-Läsion (SR 3,73).

and $0.81--1=$ almost perfect agreement [29]. Continuous scores (VAS) were compared using correlation (Pearson's) and limits of agreement [30]. Statistical analyses were performed using SPSS 17 and IBM-SPSS 19 (Chicago, Ill, USA).

\section{Results}

$\nabla$

\section{Categorical evaluation of strain images}

The qualitative classification of color distribution in the elastogram showed reduced strain in Crohn's lesions as well as adenocarcinomas indicating increased tissue hardness compared to surrounding tissue. Elastograms of an adenoma, an adenocarcinoma and a Crohn's lesion are shown in 0 Fig. 2a-c. $\odot$ Fig. 3 shows the distribution of qualitative strain image categories within each group of lesions evaluated by observer 1.29 of 33 scored cases were described as category $2 \mathrm{AB}$ or $2 \mathrm{BA}$. 


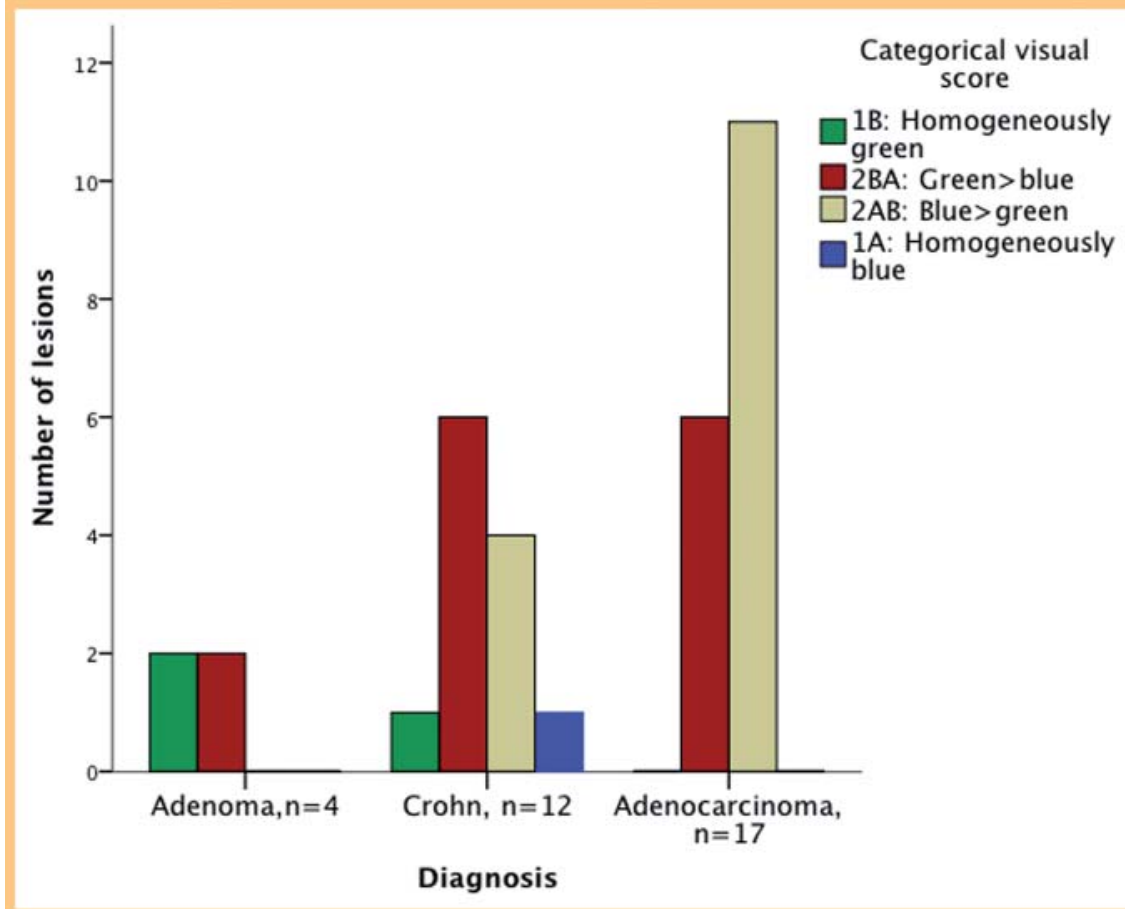

Fig. 3 A categorical visual score based on the color distribution in the lesion of interest. The bars indicate the number of lesions in each diagnostic group categorized by observer 1 .

Abb.3 Eine kategorische visuelle Bewertung aufgrund der Farbverteilung in der Läsion, die von Interesse ist. Die Säulen geben die Anzahl der Herdläsionen in jeder diagnostischen Gruppe an, kategorisiert durch Beobachter 1.

Table 1 Mean and median strain ratio (SR) and visual analog scale for the three diagnostic entities: adenoma, Crohn's lesion and adenocarcinoma. The SR intra-assay standard deviation is greater for Crohn's lesions than for adenocarcinomas indicating a larger measurement variation.

\begin{tabular}{|c|c|c|c|c|}
\hline diagnosis & $\begin{array}{l}\text { mean strain } \\
\text { ratio }^{1} \text { (SD) }\end{array}$ & $\begin{array}{l}\text { median strain ratio } \\
\text { (min, } \max \text { ) }\end{array}$ & $\begin{array}{l}\text { SR intra-assay } \\
\text { standard deviation }\end{array}$ & $\begin{array}{l}\text { Mean VAS } 2 \\
0-100 \mathrm{~mm}(\mathrm{SD})\end{array}$ \\
\hline adenoma $(n=4)$ & $1.31(0.58)$ & $1.25(0.68,2.06)$ & 0.35 & $59.8(10.4)$ \\
\hline Crohn's lesion $(n=16)$ & $3.33(5.21)$ & $2.09(1.31,22.75)$ & 1.23 & $81.7(6.3)$ \\
\hline adenocarcinoma $(n=18)$ & $2.51(1.17)$ & $2.18(0.81,5.34)$ & 0.46 & $75.2(13.3)$ \\
\hline
\end{tabular}

${ }^{1}$ Mean SR: Crohn's lesion vs. adenocinoma: $p=0.537$. Mean SR: Adenoma vs. adenocarcinoma: $p<0.001$.

${ }^{2}$ VAS: Crohn's lesion vs. adenocarcinoma: $p=0.092$. VAS: Adenoma vs. adenocarcinoma: $p<0.001$.

\section{Semi-quantitative evaluation of strain images}

The VAS evaluation showed no significant difference between Crohn's lesions and adenocarcinomas, while adenomas had a significantly lower VAS score indicating softer tissue. SR quantification also could not demonstrate any difference between Crohn's lesions and adenocarcinomas. However, the four adenomas had a significantly lower SR than the adenocarcinomas. The mean SR as well as median SR, intra-assay standard deviation, and VAS score for each diagnostic group are summarized in $\bullet$ Table 1 and the GEE model details are listed for VAS and SR in appendices 1 and 2 , respectively.

\section{Interobserver validation of categorical and semi-quantitative elastography}

For the categorical evaluation, cine loops of 28 of the original 33 lesions were re-evaluated by an observer blinded to the clinical data. Five cases were excluded from re-evaluation because only still images were stored and not the original video files. A comparison between observer 1 (original) and observer 2 (blinded) yielded a Kappa value of 0.38 for the categorical scale, indicating fair interobserver agreement. The second observer also repeated the VAS scoring in 30 of the 35 cases that had previously been scored by observer 1 . There was a significant correlation between the two observers (Pearson's $r=0.55, p=0.002$ ). The correlation plot and lim- its of agreement between observer 1 and 2 are shown in $\bullet$ Fig. 4 . Moderately good correlations were found with better interobserver agreement and correlation for higher values of VAS than for mid-range values.

\section{Intraobserver validation of strain ratio measurements}

The comparison between triplets of SR recorded in separate loops at different levels of E-dyn is presented in 0 Table 2. We found moderate to good correlations (Spearman's rho $=0.47-0.82$ ) between the separate recordings with different E-dyn ranges. A comparison of the median SR showed no significant differences between recorded SR measurements between E-dyn levels 2 and 6 or between E-dyn levels 4 and 6. However, there was a significant difference in SR at E-dyn levels 2 and 4. The intra-assay standard deviations for all SR measurements in individual lesions are listed according to diagnosis in 0 Table 1 . These values showed higher measurement variation for Crohn's lesions than for adenocarcinomas.

\section{Assessment of fibrosis}

The number of included patients, scanned sections, the macroscopic length and the categorical fibrosis score for each of the three diagnostic groups are presented in $\bullet$ Table 3 . There was no significant difference in the macroscopic length of Crohn's steno- 

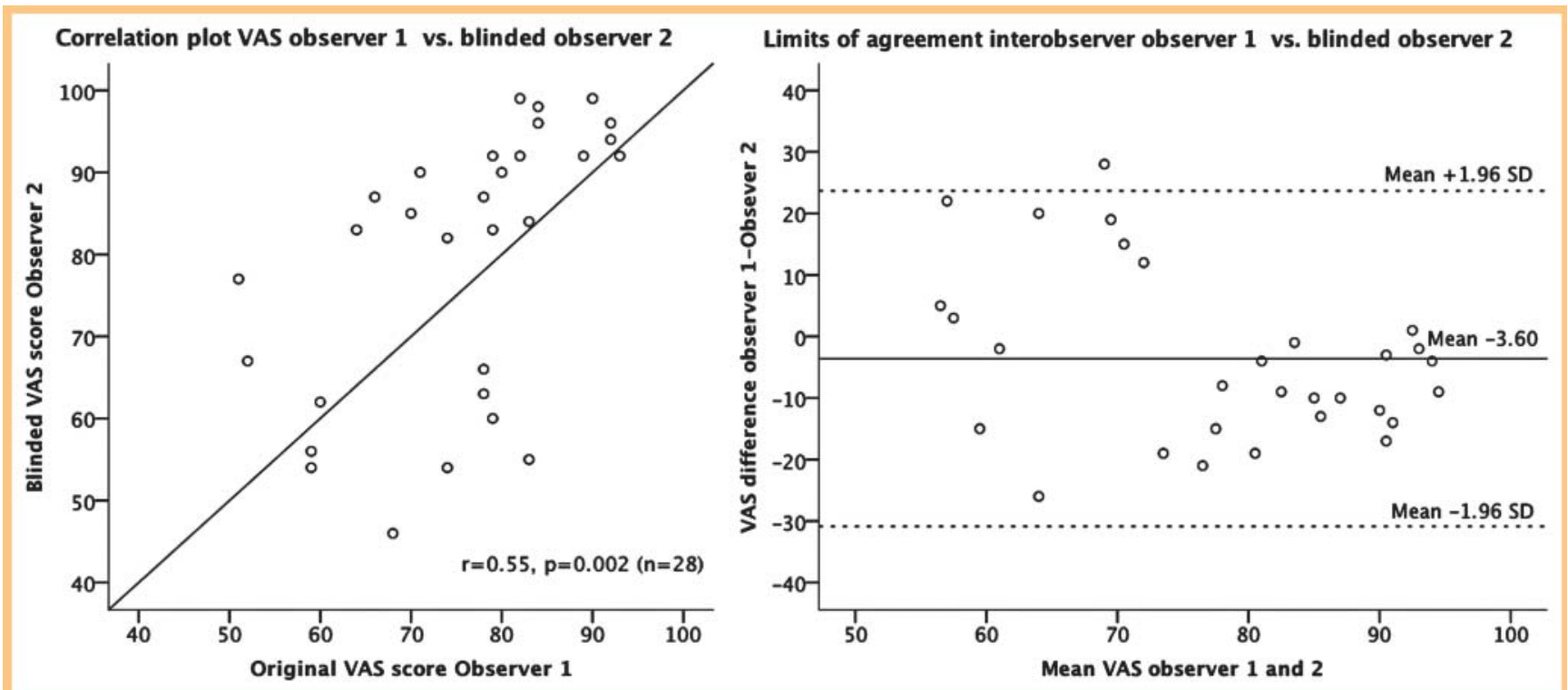

Fig. 4 Correlation plot and limits of agreement plot of VAS score agreement between observer 1 and observer 2. Observer 2 was blinded to the clinical data. The agreement improved with higher VAS scores.

Abb. 4 Korrelationsplot und „Limits of agreement“-Plot der Übereinstimmung von Beobachter 1 und 2 bei der VAS-Auswertung. Beobachter 2 kannte die klinischen Daten nicht (Verblindung). Die Übereinstimmung verbesserte sich mit höherer VAS-Punktzahl.

Table 2 Comparison of median strain ratio measurements of the same lesions with elasticity dynamic range (E-dyn) levels 2, 4 and 6 . The differences were not normally distributed. The exact two-tailed Wilcoxon-Mann-Whitney test was used for the comparison of paired differences. The significance level for differences was set to $p \leq 0.05 / 3=0.017$ to adjust for multiple comparisons.

\begin{tabular}{lllll}
$\begin{array}{l}\text { E-dyn levels } \\
\text { compared }\end{array}$ & $\begin{array}{l}\text { Pairs } \\
\mathbf{n}\end{array}$ & median SR (min-max) & $\begin{array}{l}\text { Spearman's correlation: } \\
\text { rho (p-value) }\end{array}$ & P-value of paired differences \\
\hline $\begin{array}{l}\text { E-dyn } 4 \\
\text { E-dyn 2 }\end{array}$ & 34 & $2.25(0.68-8.28)$ & $0.47(0.005)$ & 0.008 \\
\hline E-dyn 4 & 35 & $1.74(0.81-30.79)$ & $0.55(0.001)$ & $0.849(\mathrm{n} . \mathrm{s})$ \\
E-dyn 6 & 34 & $2.25(0.68-8.28)$ & $0.82(<0.001)$ & $0.022(\mathrm{n} . \mathrm{s})$ \\
\hline E-dyn 2 & & $2.06(0.33--22.75)$ & \\
E-dyn 6 & & $1.74(0.81--30.79)$ & & \\
\hline
\end{tabular}

\begin{tabular}{|c|c|c|c|c|c|}
\hline \multirow[t]{2}{*}{ diagnosis } & \multirow[t]{2}{*}{ patients } & \multirow[t]{2}{*}{ lesions } & \multirow{2}{*}{$\begin{array}{l}\text { macroscopic length } \\
(\min -\max )(\mathrm{cm})\end{array}$} & \multicolumn{2}{|c|}{ fibrosis score $(0-3)$} \\
\hline & & & & Score & $\mathbf{n}$ \\
\hline \multirow[t]{4}{*}{ adenocarcinoma } & \multirow[t]{4}{*}{$16^{*}$} & \multirow[t]{4}{*}{18} & \multirow[t]{4}{*}{$3.75(1.3-7.5)$} & Score 0 & 0 \\
\hline & & & & Score 1 & 5 \\
\hline & & & & Score 2 & 13 \\
\hline & & & & Score 3 & 0 \\
\hline \multirow[t]{4}{*}{ Crohn's lesion } & \multirow[t]{4}{*}{9} & \multirow[t]{4}{*}{16} & \multirow[t]{4}{*}{$3.50(2.0-15.0)$} & Score 0 & 0 \\
\hline & & & & Score 1 & 2 \\
\hline & & & & Score 2 & 10 \\
\hline & & & & Score 3 & 4 \\
\hline \multirow[t]{4}{*}{ adenoma } & \multirow[t]{4}{*}{3} & \multirow[t]{4}{*}{4} & \multirow[t]{4}{*}{$2.35(1.0-3.5)$} & Score 0 & 2 \\
\hline & & & & Score 1 & 0 \\
\hline & & & & Score 2 & 2 \\
\hline & & & & Score 3 & 0 \\
\hline
\end{tabular}

Table 3 Descriptive data for the diagnostic entities adenocarcinoma, Crohn's lesion and adenoma including the number of patients, number of lesions, macroscopic length and number of lesions categorized using the $0-3$ fibrosis score by the pathologist. One patient had both an adenocarcinoma and an adenoma and was counted twice. A total of 27 patients were included. ses and the maximum length of the adenocarcinomas. The adenomas were smaller than the adenocarcinomas and Crohn's lesions. In two separate evaluations, one pathologist visually categorized the fibrosis in 37 sections of the same lesions as 2 = "moderate fibrosis" in 25 and 17 cases, respectively. Category
1 = "slight fibrosis" was used 7 and 13 times, respectively. The two separate evaluations with categorical fibrosis scores 0 -3 had a Kappa value of 0.37. In the Crohn's lesions, the fibrosis score indicated variations in fibrosis in different wall layers. The mean 
fibrosis scores were as follows: submucosa -2.44 , subserosa 1.75 and proper muscle -1.50 .

\section{Assessment of inflammation in Crohn's specimens}

The patients diagnosed with Crohn's disease all had pain as the main symptom with stenotic findings in the small or large bowel confirmed by radiological imaging or endoscopy. Eight of nine patients were non-responders to high-dose steroids or TNF-antagonists. Two of the patients who underwent surgery in 2008 were reluctant to use TNF-antagonists or prednisolone. Two patients who underwent surgery only 3 and 8 months after diagnosis had suffered substantial weight loss of 10 and $15 \mathrm{~kg}$, respectively. One Crohn's patient was operated on under the suspicion of cancer in the ascending colon, although histopathology had not confirmed this prior to surgery. This patient had only received a 10-day course of antibiotics prior to surgery. All Crohn's lesions exhibited transmural inflammatory changes. Lymphoplasmacytic inflammation was assessed as slight in 4/16 cases, moderate in $8 / 16$ cases and severe in $4 / 16$ cases. Other inflammatory parameters were mucosal ulcerations in $13 / 16(81 \%)$ cases, granulation tissue in $12 / 16(75 \%)$ cases, cryptitis in $7 / 16$ (44\%) cases, fissure ulcers in $4 / 16(25 \%)$ cases, fistulas in $3 / 16$ $(19 \%)$ cases and abscesses in 0/16 cases. Lesions with high overall inflammatory activity did not differ from lesions with low overall inflammatory activity by fibrosis score. Furthermore, there was no difference in SR or VAS between lesions with overall high or low inflammatory activity. Inflammatory changes in the adenocarcinomas and adenomas were not specifically evaluated. However, none of these specimens exhibited transmural chronic inflammatory changes. Only one adenocarcinoma specimen also contained an area of acute inflammation and abscess formation according to the original pathology report.

\section{Strain evaluation by tumor stage and grade}

The SR and VAS results were compared by tumor stage according to the TNM classification for the 18 examined sections of malignant lesions. The results are summarized in $\bullet$ Table 4 . There was a tendency for a higher fibrosis score for tumors staged as T3 or T4. We found no significant differences in SR and VAS between lesions staged as $\mathrm{T} 3$ or $\mathrm{T} 4$ compared to $\mathrm{T} 1$ and $\mathrm{T} 2$, but the included numbers were low. The tumor grade was described as highly differentiated ( $>95 \%$ glandular structures) in 2 cases, moderately differentiated (50-95\% glandular structures) in 9 cases and poorly differentiated ( $<5 \%$ glandular structures) in 7 cases. When highly and moderately differentiated tumors were considered as one group $(n=11)$ and compared to poorly differentiated tumors $(n=7)$, we found no significant differences in the SR or VAS scores. The number of lesions given fibrosis score 2 was $8 /$ $11(73 \%)$ for the highly and moderately differentiated adenocarcinomas and $5 / 7(71 \%)$ for the poorly differentiated adenocarcinomas.

\section{Discussion \\ $\nabla$}

\section{Differentiation between neoplastic and inflammatory lesions by RTE}

RTE demonstrated low strain indicating harder tissue in resected lesions from both colorectal carcinomas and Crohn's disease. The hypothesis that strain imaging could differentiate malignant neoplastic lesions from benign lesions caused by inflammation was based upon observations that malignant tumors in other organs tended to become harder than benign lesions [14, 19, 31 - 33]. Pathologists frequently observe increased fibrosis within and in the vicinity of malignant lesions. A similar process also occurs in chronic inflammation in which case fibroblasts and possibly other cells produce collagen-rich interstitium resulting in scar tissue [34]. Such fibrogenic activity seems to be a dominant feature in stenotic lesions of Crohn's disease. A second contributor to the hard appearance of malignant tumors may be high interstitial pressure $[23,25,35,36]$, which decreases quickly after devascularization. Hence, its probable contribution to differences in tissue elasticity was not measureable in our study on ex-vivo tissue specimens. Crohn's disease is usually subjected to surgery because of intractable stenosis not responding to medical therapy. All Crohn's lesions in our study had extensive fibrosis, as demonstrated by histology. Hence, increased tissue hardness was visualized in both Crohn's lesions and adenocarcinomas. However, it was not possible to detect any strain differences between benign transmural lesions caused by chronic inflammation and malignant tumors.

\section{Strain evaluation and fibrosis in adenocarcinomas}

The number of adenocarcinomas in the study was limited. Hence, we could not find a statistically significant difference in SR or VAS score, but there was a tendency to increase the fibrosis score and SR with increasing tumor stage. With respect to tumor grading, we would expect poorly differentiated tumors to have a higher fibrosis score. However, no significant strain differences were found, even if both the SR and VAS scores showed an insignificant tendency towards higher strain for poorly differentiated tumors. The low number of lesions included may be the cause for this (type 2 error), and larger studies are warranted.

\section{Strain assessment}

A majority of published papers on RTE have used visual categorical scoring based on color distribution in the lesion as the main strain evaluation tool. In this study, we applied a categorical classification based on a distribution pattern and predominance of separate colors within the lesions. This classification was introduced by Janssen et al. [28] for the evaluation of pancreatic lesions using endoscopic ultrasonography, and up to five of the original categories were used in our study. The qualitative scoring system could not reliably separate the diagnostic entities in this study. Observer 1 classified $50 \%$ of the adenomas, $50 \%$ of the Crohn's lesions and $35 \%$ of the adenocarcinomas as $2 \mathrm{BA}$, indicating more green than blue. Category $1 \mathrm{~B}$, with a homogeneously

\begin{tabular}{|llllll|}
$\begin{array}{l}\text { adenocarcinomas, } \\
\text { T-stage }\end{array}$ & $\mathbf{n}$ & $\begin{array}{l}\text { fibrosis } \\
\text { score }=\mathbf{1}\end{array}$ & $\begin{array}{l}\text { fibrosis } \\
\text { score = }\end{array}$ & $\begin{array}{l}\text { median SR } \\
\text { (min-max) }\end{array}$ & $\begin{array}{l}\text { VAS score } \\
\text { (mean, SD) }\end{array}$ \\
\hline T1 & 2 & 1 & 1 & $1.73(1.62-1.84)$ & $62.5(4.95)$ \\
\hline T2 & 2 & 1 & 1 & $1.56(0.81-2.31)$ & $72.0(16.97)$ \\
\hline T3 & 8 & 3 & 5 & $3.00(1.19-5.34)$ & $81.1(11.05)$ \\
\hline T4 & 6 & 0 & 6 & $2.41(1.59-3.18)$ & $72.2(15.29)$ \\
\hline
\end{tabular}

Table 4 Fibrosis score, strain ratio and VAS score for adenocarcinomas according to tumor stage. 
green presentation, was only used for benign lesions, but only 3 of 16 benign lesions were categorized as $1 \mathrm{~B}$. The interobserver reproducibility of categorical scoring was fair (Kappa: 0.38 ) when the cine loops were re-evaluated by a second observer.

Elastograms were also evaluated with a continuous VAS score, anticipated to be more fine-grained than the categorical score, and comprising an aspect of strain comparison between the lesion and the surrounding reference tissue. Because none of the lesions were perceived as softer than the reference tissue, the lower half of the scale was not utilized. VAS evaluation had a moderate correlation $(r=0.55)$ between the original and an observer blinded to clinical data. The difference between the observers was larger for low scores (moderately hard and mixed lesions) than for high scores (harder lesions) ( 0 Fig.4). This coincides with an observation that two observers frequently scored the same lesions as $2 \mathrm{AB}$ (inhomogeneous, blue $>$ green) and 2BA (inhomogeneous, green > blue), correspondingly, on the categorical scale.

The SR is based on a computer-based comparison of mean strain in two selected areas, and may thus seem to be more objective than the VAS and the categorical scale. However, the selection of calculation areas is still user-dependent, and the recorded strain may be subject to significant variations especially in heterogeneous reference areas. Uneven application of stress within the elastogram ROI may also influence the SR results. Hence, SR evaluation is usually quoted as a semi-quantitative method. The SR data ( $\bullet$ Table 1 ) demonstrates a large spread in strain measurements within the groups of Crohn's lesions and adenocarcinomas. The variation between cases in the same group may express measurement variation and also reflect a biological diversity in tissue strain for that entity.

\section{Reproducibility of SR measurements}

The E-dyn level of RTE influences the color presentation of strain distribution profoundly [37]. Consequently, it is crucial to keep this setting on a standardized level for the visual comparison of strain images in different cases. Median SR recordings at E-dyn 4 vs. 6 and E-dyn 2 vs. 6 were not significantly different. A significant difference was found for the SR recorded at E-dyn 2 vs. 4. This was an unexpected and probably unreliable result since such a difference was not found with a larger E-dyn span between 2 and 6. We have previously shown that SR measurements are independent of E-dyn level in a standardized liver-tissue-mimicking phantom [38]. Therefore, we interpreted the observed SR measurement variability as the result of the general variability of this method in separate recordings of the same lesions using a free-hand application, and not as a consequence of the selection of different levels of E-dyn. More dedicated studies may be required to confirm the relationship between E-dyn level and SR measurements in biological tissues.

\section{Relevance}

The differentiation between colorectal tumors and Crohn's lesions predominantly in the small intestines may seem to have limited clinical value. However, these lesions were chosen as a model for lesions caused by benign inflammation and malignant neoplasms in the bowel wall. We selected Crohn's lesions because they are transmural and expand the bowel wall in a similar manner to neoplasias. Rustemovic et al. have studied patients with ulcerative colitis and compared them to patients with Crohn's disease and healthy controls in vivo [39]. They found a significantly higher SR in Crohn's patients than in ulcerative colitis patients with active rec- tal disease. In the case of Crohn's disease, the patients with active disease also had a significantly higher SR than those in remission, indicating a substantial contribution from increased interstitial pressure. In the case of ulcerative colitis, the inflammation is limited to the mucosa and submucosa and does not create the transmural inflammation and fibrosis characteristic for Crohn's disease. From our point of view, the contribution of endoscopic RTE in the differentiation between Crohn's disease and ulcerative colitis may not provide more than visualization of the transmural inflammation resulting in bowel wall thickening clearly visible by B-mode EUS. However, further studies may investigate whether a possible clinical application of EUS-elastography may be the evaluation of polyps and pseudo-polyps in ulcerative colitis, and whether a thickened bowel wall with increased tissue hardness may indicate the development of malignancy in a patient with ulcerative colitis under surveillance.

Very few adenomas were included in this study, as the main object was to evaluate Crohn's lesions and adenocarcinomas. However, we found that adenomas appeared to have higher strain and, correspondingly, lower strain ratios than both adenocarcinomas and Crohn's lesions. The difference in strain properties between adenomas and adenocarcinomas in the rectum is clinically relevant, and endorectal ultrasonography (ERUS) with elastography can potentially be a valuable preoperative diagnostic tool [33]. ERUS is currently acknowledged as the best method for selecting patients for minimally invasive rectal surgery such as endoscopic mucosal resection or transanal endoscopic microsurgery $[40,41]$. The preoperative classification of early rectal adenocarcinomas and adenomas remains challenging and there is still a need for improved methods in the staging of these tumors.

\section{Limitations of the study}

This study was performed on surgically resected specimens, in which the contribution of interstitial pressure as a source of tissue hardness is eliminated. Hence, the ex-vivo setup may underestimate tissue hardness in vascularized tissue. However, all surgical specimens were examined under the same conditions, and the contribution from interstitial pressure should be reduced in a similar way for all samples. A second limitation is that the primary observer was not blinded to the clinical diagnosis. A second observer, blinded to clinical data, re-evaluated the elastography and B-mode video loops. The second evaluation was performed during a short time span (days) while the original scoring was performed after each examination spanning a period of 12 months. This may have caused some drifting in visual scoring over time, and may partly explain the moderate agreement for VAS and the fair agreement for the categorical score. The low number of adenomas included in this study (4) limits the validity of the statistical difference found between adenomas and adenocarcinomas.

\section{Conclusion}

Free-hand RTE of newly resected surgical specimens could not differentiate stenotic lesions caused by chronic inflammation in Crohn's disease from adenocarcinomas on the basis of differences in semi-quantitative strain measurements. The SR and VAS score showed significant strain differences between adenocarcinomas and a limited number of adenomas. Pathological evaluation showed increased tissue fibrosis in both adenocarcinomas and Crohn's lesions. The interobserver reproducibility of the visual evaluation using a VAS score and categorical scale was fair to 
moderate. The intra-assay reproducibility of SR was more reliable, but the potential influence of E-dyn settings on SR measurements could not be unequivocally affirmed. No significant differences in strain assessment were found on the basis of inflammation grade in Crohn's lesions and by tumor stage or grade in adenocarcinomas. Ultrasound elastography is a promising clinical method, but increased strain may be observed in malignant and benign lesions and further studies on strain data of different lesions in vivo are warranted.

\section{Abbreviations \\ RTE real-time elastography \\ SR strain ratio \\ E-dyn elasticity dynamic range \\ VAS visual analog scale}

\section{Appendix}

$\nabla$

\begin{tabular}{|c|c|c|c|c|c|}
\hline \multicolumn{5}{|c|}{$\begin{array}{l}\text { tissue strain by visual analog scale (VAS), } n=35 \\
\text { (GEE, linear model) }\end{array}$} & \multirow{2}{*}{ 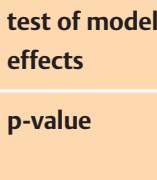 } \\
\hline & $\begin{array}{l}\text { estimated } \\
\text { marginal means }\end{array}$ & $\begin{array}{l}95 \% \text { confidence } \\
\text { interval }\end{array}$ & coefficient & $\begin{array}{l}95 \% \text { confidence } \\
\text { interval }\end{array}$ & \\
\hline diagnostic group & & & & & $<0.001$ \\
\hline adenoma $(n=4)$ & 59.8 & $(54.8,64.7)$ & -15.472 & $(-23.910,-7.035)$ & \\
\hline Crohn's lesion $(n=13)$ & 81.6 & $(78.5,84.8)$ & 6.393 & $(-1.037,13.823)$ & \\
\hline adenocarcinoma $(n=18)$ & 75.2 & $(68.5,82.0)$ & 0 & (reference) & \\
\hline
\end{tabular}

Appendix 1.

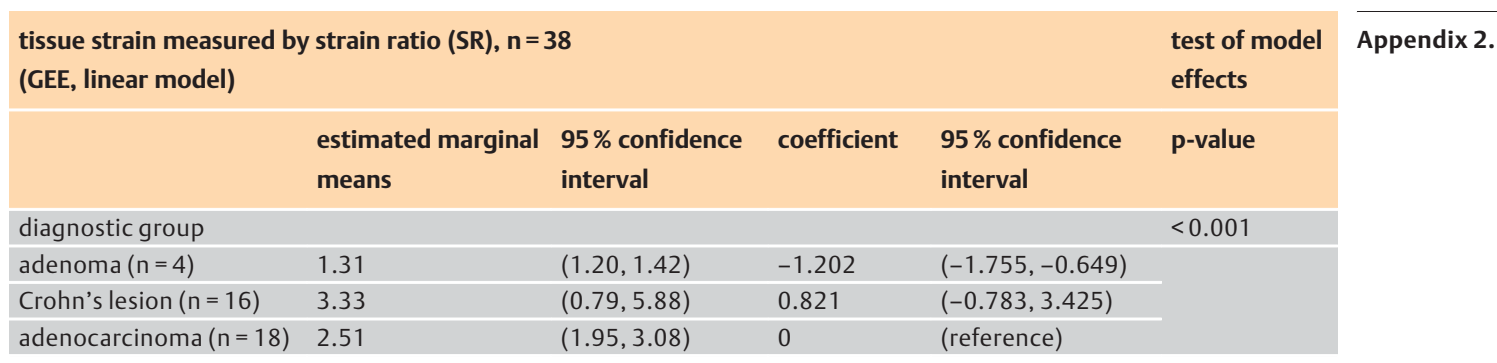

\section{Affiliations}

1 Institute of Medicine, University of Bergen

2 The Gade Institute, University of Bergen

3 National Centre for Ultrasound in Gastroenterology, Department of Medicine, Haukeland University Hospital, Institute of Medicine, Bergen

${ }^{4}$ Department of Surgery, Haukeland University Hospital, Bergen

5 Institute of Surgery, University of Bergen

\section{Acknowledgement}

$\nabla$

We thank the staff at Department of Abdominal and Emergency Surgery, Surgical Clinic, Haukeland University Hospital for their cooperation in recruiting patients and securing resected specimens. We also appreciate valuable statistical counseling from Geir Egil Eide at Centre for Clinical Research, Haukeland University Hospital.

\section{References}

1 Gregersen $H$, Matre $K$. The use of ultrasound in biomechanics. In: Ødegaard S, Gilja OH, Gregersen H eds. Basic and New Aspects of Gastrointestinal Ultrasonography Shanghai: World Scientific Publishing Co. Pte. Ltd; 2005, 23 - 74

2 Ophir J, Cespedes I, Ponnekanti $H$ et al. Elastography: a quantitative method for imaging the elasticity of biological tissues. Ultrason Imaging 1991; 13: $111-134$

3 Muller M, Gennisson JL, Deffieux T et al. Quantitative viscoelasticity mapping of human liver using supersonic shear imaging: preliminary in vivo feasibility study. Ultrasound in Med Biol 2009; 35: 219-229

4 Palmeri ML, Frinkley $K D$, Zhai $L$ et al. Acoustic radiation force impulse (ARFI) imaging of the gastrointestinal tract. Ultrason Imaging 2005; 27: $75-88$

5 Stefani L, De Luca A, Maffulli N et al. Speckle tracking for left ventricle performance in young athletes with bicuspid aortic valve and mild aortic regurgitation. Eur J Echocardiogr 2009; 10: 527-531

6 Takeuchi M, Borden WB, Nakai H et al. Reduced and delayed untwisting of the left ventricle in patients with hypertension and left ventricular hypertrophy: a study using two-dimensional speckle tracking imaging. Eur Heart J 2007; 28: 2756-2762 
7 Gilja $\mathrm{OH}$, Heimdal A, Hausken T et al. Strain during gastric contractions can be measured using Doppler ultrasonography. Ultrasound Med Biol 2002; 28: $1457-1465$

8 Iglesias-Garcia JL-NJ, Abdulkader I, Forteza J et al. Quantitative endoscopic ultrasound elastography: an accurate method for the differentiation of solid pancreatic masses. Gastroenterology 2010; 139: $1172-1180$

9 Fraquelli M, Rigamonti C, Casazza G et al. Reproducibility of transient elastography in the evaluation of liver fibrosis in patients with chronic liver disease. Gut 2007; 56: 968-973

10 Friedrich-Rust M, Ong MF, Martens $S$ et al. Performance of transient elastography for the staging of liver fibrosis: a meta-analysis. Gastroenterology 2008; 134: 960-974

11 Zhi H, Xiao XY, Yang HY et al. Semi-quantitating stiffness of breast solid lesions in ultrasonic elastography. Acad Radiol 2008; 15: 1347-1353

12 Kamoi $K$, Okihara $K$, Ochiai $A$ et al. The utility of transrectal real-time elastography in the diagnosis of prostate cancer. Ultrasound Med Biol 2008; 34: 1025 - 1032

13 Pallwein L, Aigner F, Faschingbauer $R$ et al. Prostate cancer diagnosis: value of real-time elastography. Abdom Imaging 2008; 33: 729-735

14 Bojunga J, Herrmann E, Meyer G et al. Real-Time Elastography for the Differentiation of Benign and Malignant Thyroid Nodules: A Meta-Analysis. Thyroid 2010, $1145-1150$

15 Dighe $M$, Bae $U$, Richardson ML et al. Differential diagnosis of thyroid nodules with US elastography using carotid artery pulsation. Radiology 2008; 248: $662-669$

16 Wang Y, Dan HJ, Dan HY et al. Differential diagnosis of small single solid thyroid nodules using real-time ultrasound elastography. J Int Med Res 2010; 38: 466 - 472

17 Saftoiu A, Vilmann P, Ciurea T et al. Dynamic analysis of EUS used for the differentiation of benign and malignant lymph nodes. Gastrointest Endosc 2007; 66: $291-300$

18 Tan $R$, Xiao $Y, H e$ Q. Ultrasound elastography: Its potential role in assessment of cervical lymphadenopathy. Acad Radiol 2010; 17: 849855

19 Saftoiu A, Vilmann P, Gorunescu F et al. Accuracy of endoscopic ultrasound elastography used for differential diagnosis of focal pancreatic masses: a multicenter study. Endoscopy 2011; 43: 596-603

20 de Araujo VC, Furuse C, Cury PR et al. Desmoplasia in different degrees of invasion of carcinoma ex-pleomorphic adenoma. Head Neck Pathol 2007; 1: $112-117$

21 Deak SB, Glaug MR, Pierce RA et al. Desmoplasia in benign and malignant breast disease is characterized by alterations in level of mRNAs coding for types I and III procollagen. Matrix 1991; 11: 252-258

22 Abbas O, Mahalingam M. Desmoplasia: not always a bad thing. Histopathology 2011; 58: 643-659

23 Gulliksrud K, Galappathi K, Rofstad EK. Interstitial fluid pressure and vascularity of intradermal and intramuscular human tumor xenografts. Int J Radiat Oncol Biol Phys 2011; 80: 258-264

24 Heldin $\mathrm{CH}$, Rubin $\mathrm{K}$, Pietras $\mathrm{K}$ et al. High interstitial fluid pressure - an obstacle in cancer therapy. Nat Rev Cancer 2004; 4: 806-813
25 Wiig H, Tveit E, Hultborn R et al. Interstitial fluid pressure in DMBA-induced rat mammary tumours. Scand J Clin Lab Invest 1982; 42: 159164

26 Shiina TDM, Bamber JC. Strain imaging using combined RF and envelope autocorrelation processing. In: Ultrasonics Symposium, 1996 IEEE Proceedings; 1996, 1331 - 1336

27 Shiina TYM. Fast reconstruction of tissue elastic modulus image by ultrasound. In: Engineering in Medicine and Biology 2005 Shanghai: Proceedings of 2005 IEEE; 2005, 976-980

28 Janssen J, Schlorer E, Greiner L. EUS elastography of the pancreas: feasibility and pattern description of the normal pancreas, chronic pancreatitis, and focal pancreatic lesions. Gastrointest Endosc 2007; 65: $971-978$

29 Landis JR, Koch GG. The measurement of observer agreement for categorical data. Biometrics 1977; 33: 159-174

30 Bland JM, Altman DG. Statistical methods for assessing agreement between two methods of clinical measurement. Lancet 1986; 1: 307 310

31 Zhu QL, Jiang YX, Liu JB et al. Real-time ultrasound elastography: its potential role in assessment of breast lesions. Ultrasound Med Biol 2008; 34: $1232-1238$

32 Alam F, Naito K, Horiguchi J et al. Accuracy of sonographic elastography in the differential diagnosis of enlarged cervical lymph nodes: comparison with conventional B-mode sonography. Am J Roentgenol Am J Roentgenol 2008; 191: 604-610

33 Waage JE, Havre RF, Odegaard $S$ et al. Endorectal elastography in the evaluation of rectal tumours. Colorectal Dis 2011; 13: 1130-1137

34 Lund PK, Zuniga CC. Intestinal fibrosis in human and experimental inflammatory bowel disease. Curr Opin Gastroenterol 2001; 17: 318 323

35 Lunt SJ, Kalliomaki TM, Brown A et al. Interstitial fluid pressure, vascularity and metastasis in ectopic, orthotopic and spontaneous tumours. BMC Cancer 2008; 8: 2

36 Milosevic M, Fyles A, Hill R. Interstitial fluid pressure in cervical cancer: guide to targeted therapy. Am J Clin Oncol 2001; 24: 516-521

37 Havre RF, Elde E, Gilja OH et al. Freehand Real-Time Elastography: Impact of Scanning Parameters on Image Quality and in Vitro Intra- and Interobserver Validations. Ultrasound in Med Biol 2008; 34: 1638 1650

38 Havre RF, Waage JR, Gilja OH et al. Real-Time Elastography: Strain Ratio Measurements Are Influenced by the Position of the Reference Area. Ultraschall in Med 2011, Epub ahead of print, June 2011

39 Rustemovic N, Cukovic-Cavka S, Brinar M et al. A pilot study of transrectal endoscopic ultrasound elastography in inflammatory bowel disease. BMC Gastroenterol 2011; 11: 113

40 Puli SR, Bechtold ML, Reddy JB et al. How good is endoscopic ultrasound in differentiating various T stages of rectal cancer? Meta-analysis and systematic review. Ann Surg Oncol 2009; 16: 254-265

41 Tytherleigh MG, Warren BF, Mortensen NJ. Management of early rectal cancer. Br J Surg 2008; 95: 409-423 